\title{
Art Presentation with Scientific Method, Hybridization in Annuitterra Works
}

\author{
Iqbal Prabawa Wiguna ${ }^{1 *}$
}

\author{
${ }^{1}$ Faculty of Creative Industry, Telkom University, Bandung 40257, Indonesia \\ Corresponding author. Email: iqbalpw@gmail.com
}

\begin{abstract}
This paper analyses the relationship between art and sciences in Bandung contemporary art scene. By using samples of animal bones material as art medium in Annuitterra's works. Main focus on this research is finding the relationship of scientific methods and art presentation. Annuitterra is group of collective artists domiciled in Bandung. This group focusing on exploration in the field of art, science and design for the past 4 years. The works vary from works that are strong in scientific elements such as taxidermy, skeletonizing, wet specimen, mummification, diaphanized, and plasticization to interactive works with art presentations such as bio art, sound art, scent art, ecological art. This further research explores not only finding out the narratives behind the works but also analysing the process of skeletonizing animals which they used as their main medium. The results of the analysis show that there is an interdisciplinary tendency, combination of artistic imagination and rational thought of science. Qualitative analysis shows if new forms of art are created by borrowing processes that are generally in the scientific realm. As an artist they are using scientific method, but in the end, they develop their own creative process intuitively to create visual art form to remind us of the relationship between humans and nature through death.

Keywords: art presentation, scientific method, Annuitterra
\end{abstract}

\section{INTRODUCTION}

The use of multimedia and new media in Indonesian fine art began in 1970-1980 through the New Art Movement or GSRB. This movement became important in Indonesian fine art because one of its aims was to bring down the dominance of painting, sculpture and graphics. GSRB paved the way for the use of multimedia media such as photography, video, performance and installation into a medium that was widely used by artists at that time [1].

The longevity of art and science in Indonesian art emerged after the New Order regime collapsed in 1998. House of Natural Fiber (HONF) was one of the first new media artists to use scientific methods and art presentations to emerge in Yogyakarta in 1999, followed by Lifepatch established in 2012 and XXLab established in 2013. HONF, Lifepatch and XXlab connect the philosophy of science and everyday life into their work. The elements of science and technology are very powerful in the works [2].

The relationship between art and science is one of the special concerns in contemporary art. The combination of art with new media, let say such as electronics, chemicals and animal preservation, always presents a variety of works that attract the attention of curators, critics, and public art. Bandung as one of the center for creative art and culture city in Indonesia are place where these young artists live and make their new works in studios and laboratory. There are various reasons why the city become 'magnets' for young artists to do activities there. One reason is that there are a variety of communities in this city that can unite various people with different disciplines to collaborate and create new collaborative works. the rapid development of communities in Bandung, especially since the 90 s enlivened the activities of art events in the city the emergence of alternative art spaces such as Ruang Gerilya, Omnispace, Semata Gallery and many more complemented the space for art activities after previously being dominated by galleries such as Selasar Sunaryo, Thee Huis Gallery, Lawangwangi Gallery.

The different approach of these alternative space brings more wider audience with different academic background. and not infrequently in the end some people who do not have an art background actually become an artist. One of the artists from Bandung who are non-academics of art is Annuitterra. The dialogue between art and science always presents interesting and even mesmerizing works. Contemporary artists always try to find novelty through their works. Not infrequently they use experimental techniques and very scientific methodologies [3]. The results are sometimes unexpected. besides the mediums are different and aesthetically very interesting, but more importantly provoking the question of how the work was made? 


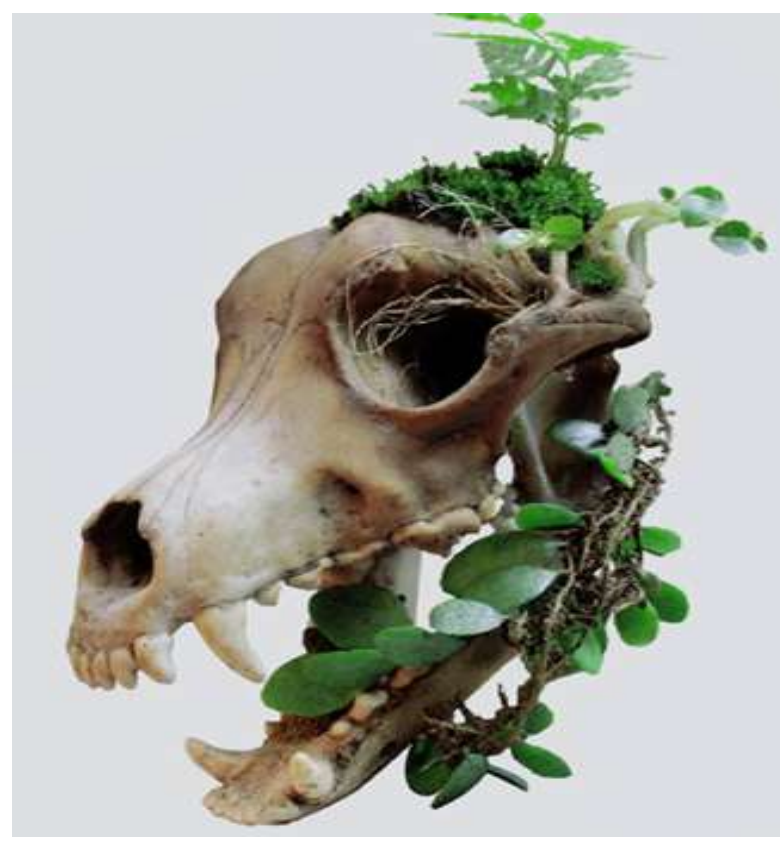

Figure 1 Annuitterra Artwork

\section{METHOD}

The research began with field research. The research approach is qualitative research. The author collected several samples of work that were considered to represent how Annuitterra's creation process. The process of collecting data included interviews, documentary photographs, followed by literature study.

The selection of artists work is based on bone preservation or skeletonizing methods as main object. By using a sample skeletonizing Annuitterra, this paper works inductively, through the conclusion of something specifically toward the general. The aim is to build a broader understanding of art practice in contemporary art, especially works that intersect with scientific methods [4].

\section{RESULTS AND DISCUSSION}

Annuitterra is a collective art group whose works expression focuses on exploration in the fields of art, science and design for the past 4 years. The works is varied, from works that are strong in scientific elements such as taxidermy, skeletonizing, wet specimen, mummification, diaphanized, and plasticization to interactive works with art presentations such as bio art, sound art, scent art, ecological art. This group was originally a solo project from a design student named Abbyzar Raffi. Abbyzar is a designer who have strong interest in the world of science, with his designer background his first project was to sell his own product that is made of bones to become a souvenir that people could wear, such as bones bracelets or bones necklace. Along with his colleague Taufik Firmansyah, Abbyzar made his first business called Wellbone in the Cipaganti Antique Market. Wellbone uses bone ma-terial obtained from slaughterhouses. The bones commonly used are the bones of cows and goats. From these bones they processed the solid and unique bone shape by using the engraving and sculpting techniques into a unique souvenir. Use products such as necklaces, bracelets and key chains to be the first product to be the main product selling.

The lack of branding, product socialization and various other factors made Wellbone's business not run smoothly. After running for 1-year Wellbone finally closed due to difficulties in sales. From the Wellbone project, Annuitterra seeds began to be formed. Abbyzar began looking for the cause of the failure on this project. In the end the experience of Wellbone made Abbyzar make a project called Annuitterra. Annuitterra in its beginning was a laboratory to develop Abyzzar interest in the world of taxidermy and skeletonizing. Taxidermy is derived from the Greek word "taxis" which means to move and "derma" which means skin. This is a form of animal preservation by removing the skin from its contents. While skeletonizing refers to the final stage of decomposition, where the last remnants of soft tissue from the corpse or carcass have decayed or dried to the point where the skeleton is exposed. At the end of the skeletonizing process, all soft tissues will be removed, leaving only articulated bones. With the knowledge from searching in the internet and the joint experience of Wellbone, Abbyzar began making several artworks that featured the results of his studies in both taxidermy and skeletonizing fields and uploading them on social media. The positive impact of social media who appreciate Abbyzar's works makes Abbyzar consistently upload the study process. The rapid publication of these works finally made Abbyzar get acquainted with several artists and curators of Bandung's contemporary art. Through this introduction Abbyzar began exhibiting with this unique medium in the realm of contemporary art.

Artist using skeleton as symbols in their works is not a strange thing because skeleton as representation in the art world has a long history. The skeleton usually used as a model for drawing, painting or sculpting. The using of real skeleton in the art world started long even before the art term was created [5]. The history of how bones become an object to be presented for either science or art shows our relationship to nature and our understanding of the animal itself. It is our curiosity and admiration for nature that makes humans find out more about nature, even in the renaissance century we know the cabinet of curiosity whose contents range from books, scientific tools, art objects to animal specimens. Presentation of art and science using animals as objects in those days is a key for us to understand human view of nature [6].

In the past the presentation of art using the skeleton as a form of human interest and admiration for nature, the presentation of the art of using skulls today can be seen as a popular symbol in pop culture. This image appears in various subculture genres, as a general representation of personal or collective freedom and forms of expression of resistance. Image of skulls and skeletons can be associated with many meanings of art depending on the context of their use they can be caricatures politics, satirical, icons, religious, anthropologists or folklore with cultural associations (such as the Mexican Day of the Dead) [7]. Skull as an icon also appear in empirical themes such as; 
premonition of death, fear of tragedy, deception, and sacrifice. The symbolism of the skull and skeleton allows artists to enjoy subjects that are reminiscent of poetry and epic tragedies. It can be said that the symbol is so popular that it can even come from ideas about love and death. Apart from the meaning of past art works with this image, the skull and skeleton are still an icon and a 'tool' to convey the ideas of contemporary artists [8].

Skeletonizing is a process of decomposition which eventually leaves bones to be exposed. Skeletonizing is the seventh stage of the eight stages of decomposition, the bone preservation process itself is called maceration. This preservation process is a process whose purpose is to get a complete skeleton of bone and finally be processed. Maceration is a skeletonizing process that is controlled.

There are various ways of bone and skeletal preservation, from these various methods the most popular are the following 3 ways: buried, soaked in water, quarantined with dermestes bacteria.

- Buried: this is the most conventional way to preserve the skeleton. The skeleton is buried in the ground and allowed to decompose by itself, usually with this process the results are bones and certain muscle or meat tissues are remaining, so it can be said that the results are rawer, this process is usually done to get a natural bone colour (brownish, yellow)

- Soaked: the process of bone soaking is usually done in a container and adding some chemical solutions such as hydrogen peroxide to whiten bones. With this process the results achieved are bones that are clean from meat and muscle tissue, with the added chemical solution hydrogen peroxide that makes the bones whitening.

- Quarantine with a bacterium: dermestes beetle is a beetle that consumes dry animal carcasses, it will eat up all parts of the animal's body and leave only the skeleton, the result of this process is the bone which is white and clean from the skin of muscle tissue and flesh [9].

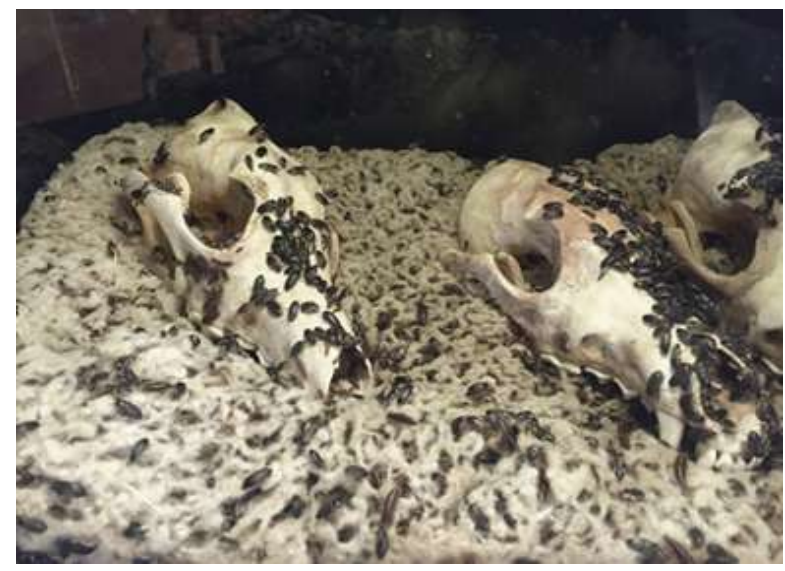

Figure 2 The process of macerating with dermestes beetles

After experimenting with different methods, Annuitterra usually creating the skeletonizing work using a soaked method. This method was chosen after experimenting with two other methods, and due to efficiency and a safer process this method is frequently used in the macerating process.

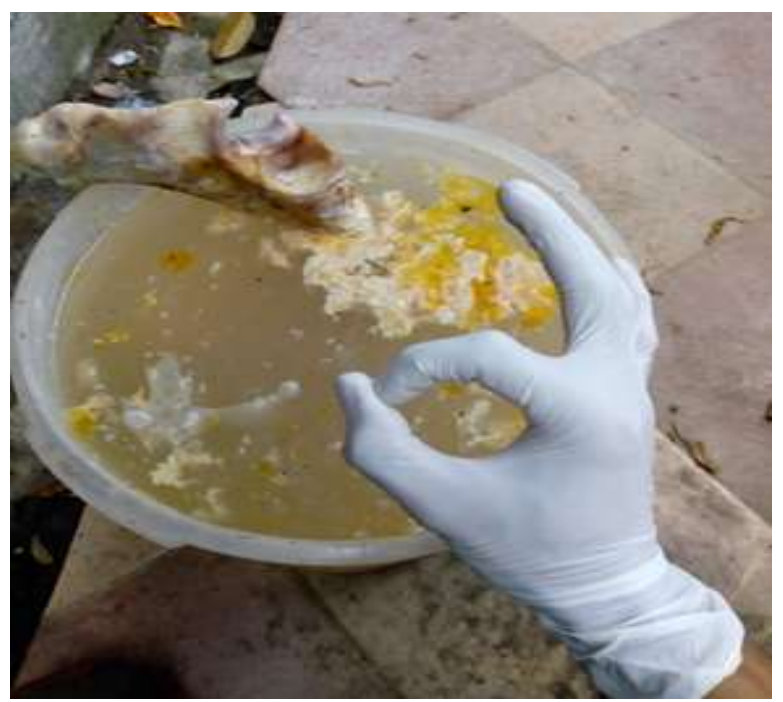

Figure 3 The process of soaking the bone with sodium hydroxide

After the specimens have been obtained (usually a road kill animal or donated dead pets) the specimen is skinned for taxidermy process while the internal part of the organ removed to for wet specimen process. to remove the odor and clean up bacteria that can make the specimen decomposed, the skeletal part of the bone that has been cleaned is soaked in a container filled with a chemical solution containing sodium hydroxide for 4-8 hours (depending on the size of the animal), after the sodium hydroxide-soaked process the bones need to be soaked again with gasoline for another 6-8 hours to clean the remaining small tissue. After that, dry the bone in an open space for 1 full day to eliminate the smell of gasoline, as an option if there is a need to bring white colour to the bone soak bone for another 2 days in a container full of hydrogen peroxide [10].

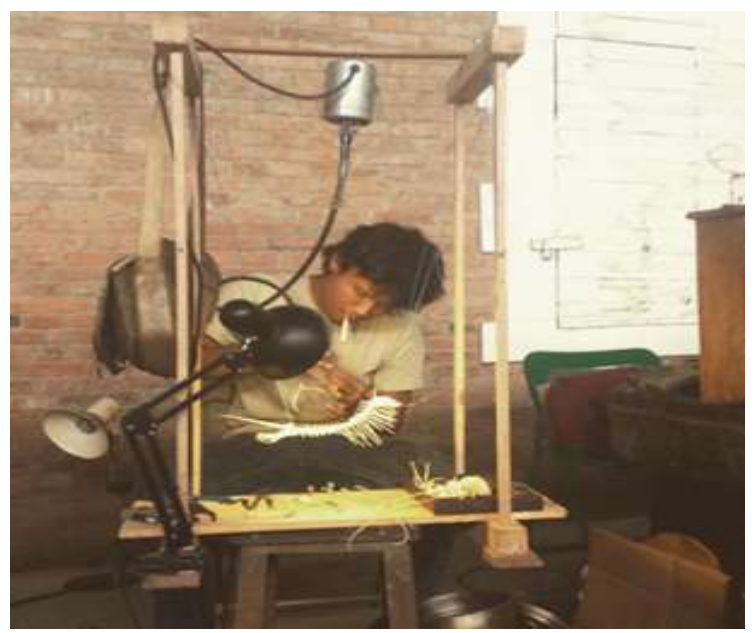

Figure 4 The process of articulating 
After the bone is dried, the bone is ready to be assembled into a complete skeleton. For that process we need an aluminium wire, screws, wood base, hand drill, wood glue. The process of assembling the bone need a full focus, because the process itself requires hand skills and knowledge of the position of the skeleton, that's because after the process of soaking the specimen the bone position has changed like a puzzle with tens and even hundreds of bones pieces. Guided by an anatomy book, Bones are rearranged without being permanently connected, just to see the big pictures, after the bones are arranged together and seems that every piece is in its place. The bone is drilled in the soft part of the bone, and then given a wire that would lock the joint. To secure the position of the wire, the bone is added some glue to make it even stronger. Wood base is needed and also a frame wire as a support, so process of assembling the skeleton would be faster. This process usually takes 1 to 2 days depending on the size of the animal.

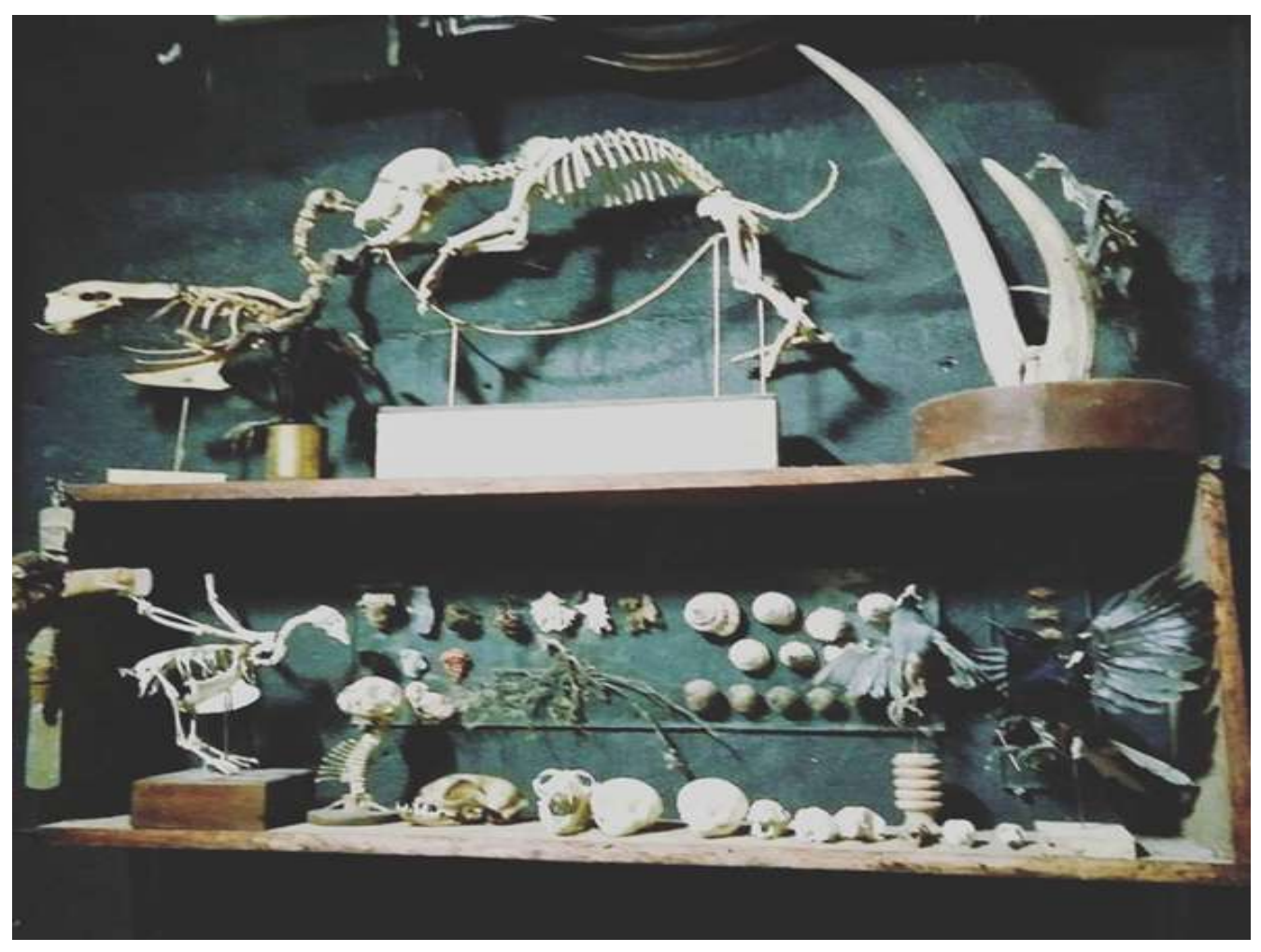

Figure 5 The work of Annuitterra's articulating skeleton

\section{CONCLUSION}

Annuitterra art presentation with scientific methodology enriches the exploration of the medium for Indonesian contemporary art. Because they are dealing with animal specimens interdisciplinary study is inevitable, make the artists must learn the anatomy and preservation process in which widely used in the world of science. But besides the unique medium and unusual methods, the works of Annuitterra also have important messages in it. A concept, that offering a different perspective on death. The works also shows how humans and nature relate at this period of time. The works can be said as a social criticism for the urban citizens. their works is a "sound" for the animals that died on the road. A reminder of how humans, especially who live in the city, have changed nature in such a way and forgetting the animals that they are slow but sure removed from their habitat and eventually become carcasses on the streets.
In a condition where the works of new mediums continue to develop and become new media conventions. Annuitterra bones preservation and skeletonizing method bring important aspect that can be appealing to artist and scientist, and that is by using scientific method and imaginative art presentation we can bring new forms of art that are visually intriguing.

\section{REFERENCES}

[1] Edwin Jurriëns (2019) Intertwined Ecologies, Third Text, 33:1, 59-77, DOI:

$10.1080 / 09528822.2018 .1538037$

[2] Golinelli, Stefano. Ruivenkamp, Guido "Do-ItYourself Biology Action Research Within The Live Sciences" Action Research 2016, Vol. 14(2) 151-167 DOI: $10.1177 / 1476750315586636$ 
[7] Stephen T. Asma."Stuffed Animals and Pickeld

[3] Eduardo Kac "Signs of Life Bio Art and Beyond" The MIT Press 2006. p. 313-387

[4] Leavy Patricia "Method Meets Art, Arts-Based Research Practice" The Guilford Press. 2015. p. 160179

[5] Aloi Giovanni. "Speculative Taxidermy" Columbia University Press, 2018. p. 43-103

[6]Baker Steve "Postmodern Animal" Reaktion Books, 2000, p. 26-39
Heads: The Culture And History Of Natural History Museums" Oxford Academy Press, 2001 p.114-202

[8] Petra Lange-Berndt (2014) A Parasitic Craft: Taxidermy in the Art of Tessa Farmer, The Journal of Modern Craft, 7:3, 267-284, DOI: $10.2752 / 174967714 \mathrm{X} 14111311182802$

[9] Anantharman Divya. "Stuffed Animals: A Modern Guide to Taxidermy" Countryman Press, 2012. p. 25-48

[10] Marbury Robert “Taxidermy Art_A Rogue's Guide to the Work, the Culture, and How to Do It Yourself” Artisan 2014. p. 300-315 